\title{
STUDI BATIK TANAH LIEK KOTA PADANG (Studi Kasus di Usaha Citra Monalisa)
}

\author{
Nana Oktora ${ }^{*}$, Adriani $^{2^{*}}$ \\ Program Studi Pendidikan Kesejahteraan Keluarga Jurusan Ilmu Kesejahteraan Keluarga \\ Fakultas Pariwisata dan Perhotelan \\ Universitas Negeri Padang \\ Jl. Prof. Dr. Hamta, Air Tawar Padang, Kel. Air Tawar Barat, Kec. Padang Utara, Kota Padang, Kode Pos 25171 \\ Sumatera Barat. Indonesia \\ Email: nana25oktora@gmail.com
}

\begin{abstract}
Abstrak
Masalah dalam penelitian ini yaitu Batik Tanah Liek Citra Monalisa mengangkat dan mengembangkan kembali Batik Tanah Liek yang dulu sempat punah dengan cara membuat kembali motif-motif yang memang sudah menjadi ciri khas dari Minangkabau. Tujuan penelitian adalah untuk mendeskripsikan tentang bentuk motif Batik Liek Citra Monalisa. Metode penelitian menggunakan metode deskriptif kualitatif. Jenis data berupa data primer dan skunder. Teknik pengumpulan data melalui observasi, wawancara dan dokumentasi. Teknikanalisa data dilakukan model interaktif yang berkaitan dengan pokok permasalahan yaitu dengan reduksi data, penyajian data, dan pengambilan kesimpulan. Hasil penelitian yaitu Motif Tanah Liek Citra Monalisa dianataranya motif alam benda meliputi motif Rumah Gadang, Jam Gadang, Tabuik, Kapal Malin Kundang dan Rangkiang. Motif flora meliputi motif Sirih Gadang, Bungo Melati dan Bungo Rayo. Motif fauna meliputi motif Kabau Padati dan Burung Hong.
\end{abstract}

Kata Kunci: motif batik, tanah like.

\begin{abstract}
The problem in this study is the Citra Liek Batik Monalisa raised and redeveloped the Tanah Liek Batik which used to be extinct by making motifs that had become the hallmark of Minangkabau. The aim of the study was to describe the shape of the Batik Liek Citra Monalisa motif. The method of research uses a qualitative descriptive method. Types of data in the form of primary and secondary data. The technique of collecting data through observation, interviews and documentation. Techniques of data analysis carried out interactive models related to the subject matter, namely by data reduction, data presentation, and conclusion. The results of the study were the Monalisa Image Liek Motif, which included natural motifs of objects including the motifs of the Gadang House, Gadang Clock, Tabuik, Malin Kundang Ship and Rangkiang. Flora motifs include Sirih Gadang motifs, Bungo Melati and Bungo Rayo. The fauna motif includes the Kabau Padati and Hong Bird motifs.
\end{abstract}

Keywords: batik motif, liek soil.

\section{PENDAHULUAN}

Batik merupakan salah satu bentuk budaya bangsa yang mempunyai keunikan dalam seni maupun teknik dan telah diakui oleh masyarakat Indonesia. Batik pada saat ini telah menjadi kebanggaan bangsa Indonesia di mata dunia, yang mana menurut Santaso (2010:1) "Batik telah diakui sebagai budaya bangsa Indonesia yang telah dikukuhkan pada tanggal 2 oktober 2009 UNESCO sebagai kekayaan budaya dunia (world culturan heritages)".Batik tidak hanya berkembang di Jawa, namun juga ada di Sumatera Barat, Jambi, Bengkulu, Lampung dan tentunya memiliki cirri khas dan karakteristik yang berbedabeda disetiap daerah, baik dari segi bentuk, dan motif.
Kerajinan batik yang terdapat di Sumatera Barat salahsatunyayaitu batik tanahliek atau disebut juga dengan batik khas Minangkabau dengan keunikan tersendiri.

Usaha batik Citra Monalisa merupakan yang pertama sekali menciptakan, mengembangkan dan mengenalkan kembali batik tanah like yang dulu sempat hilang pada masa penjajahan Jepang. Batik tanah lie Citra Monalisa dari segi bahan, motif dan teknik pembuatannya memiliki cirri khas dan karakteristik tersendiri. Sampaisaatini, produksi batik tanah liek Citra Monalisa masih unggul 
danlebihdikenal di banding kedua tempat produksi batik tanah liek yang ada di Kota Padang.

Berdasarkan observasi awal wawancara langsung dengan pimpinan Citra Monalisayaituibu $\mathrm{Hj}$.Wirda Hanim (10 November 2014) dapat dijelaskan bahwa Batik Tanah LiekCitra Monalisa ini ikut melestarikan kembali batik Tanah Liek di Sumatera Barat yang hamper punah. Batik ini di perkenalkan kembali pada tahun 1994 oleh Wirda Hanim. Awalnya Wirda Hanim melihat batik ini digunakan oleh beberapa bundo kandung di Nagari Sumani, Kabupaten Tanah Datar, Sumatera Barat. Beliau tertarik dengan batik yang langka tersebut dan berniat untuk membangkitkan kembali seni kerajinan batik Tanah Liek yang hamper punah.

Hj.Wirda Hanim adalah seorang wanita kelahiranan Batusangkar 8 Mei 1952, Nagari Sumani, Kabupaten Tanah Datar, Sumatera Barat.Di Citra Monalisa bahan pewarnaan batik tanah liek benar-benar menggunakan tanah liat dan bahan alami seperti: gambir, kulit jengkol, kulit bawang dan daun rambutan, sehingga menghasilkan warna batik yang unik dan berbeda dengan batik pada umumnya. Pada pembuatan desain motif dibuat sendiri oleh ibu Hj. Wirda Hanim sebagai pimpinan. Pembuatan motif batik diperoleh dari mencari dan meniru motif-motif dari kain batik tanah liek kuno yang ada di kampunya (Nagari Sumani, Kabupaten Tanah Datar, Sumatera Barat). Motif kuno tersebut adalah motif kuda laut dan burung hong. Wirda Hanim juga mengambil motif minang dari ukiran dan pakain, serta membuat motif yang baru dan mengembangkannya. Motif tersebut distilasi kembali supaya sesuai dengan kemungkinan untuk dijadikan motif batik, dengan kata lain perpaduan motif hias Minangkabau dengan motif stilasi Citra Monalisa diharapkan dapat menghasilakan batik yang unik.

\section{KAJIAN TEORI}

\section{Batik}

Mila (2010:9) mengatakan bahwa "Batik adalah suatu kegiatan yang berawal dari kain dengan menggunakan lilin batik (malam), kemudian diteruskan dengan pemberian warna". Menurut Hamzuri (1981: 2) "Batik adalah lukisan atau gambar pada mori yang dibuat dengan menggunakan alat bernama canting”. Melukis, menggambar atau menulis pada mori memakai canting disebut membatik (bahasa Jawa: mbatik). Membatik menghasilkan batik atau batikan berupa macammacam motif dan mempunyai sifat-sifat khusus yang dimiliki oleh batik itu tersebut.
Gorga Jurnal Seni Rupa

Volume 08 Nomor 01 Januari-Juni 2019

p-ISSN: 2301-5942 | e-ISSN: 2580-2380

Berdasarkan pendapat di atas, dapat disimpulkan bahwa kata batik terbentuk dari dua kosa kata mba dan tik yang jika keduanya disatukan akan memiliki arti membuat titik dan batik merupakan kain yang memiliki gambar hias yang dibentuk dengan proses perintangkan lilin atau malam kemudian diwarnai dengan zat warna. Batik juga merupakan kerajinan yang memiliki nilai seni tinggi dan merupakan seni melukis pada kain putih mulai di tutup dengan malam menggunakan canting, penculupan warna dan penghilangan malam atau pelorotan.

\section{Batik Tanah Liek}

Bila dilihat dari bahan pewarnaan yang digunakan dan cara pembuatan, teknologi pembuatan batik Tanah liek ini merupakan teknologi tertua dalam pembuatan batik di Indonesia. Diduga batik ini muncul dari pengaruh budayaan Cina. Menurut Elliott (2004:22) menerangkan bahwa: "Teknik rintang warna menggunakan material-material alami seperti lilin, beras dan umbi-umbian yang dilumutkan, bahkan lumpur yang di bubuhkan pada selembar kain dilumutkan dimana-mana, sejak sebelum masehi di mesir pada masa dinasti Tang abad ke-8 di Cina, bahkan di Afrika, India juga Jepang hingga saat ini”. Teknik membatik tidak hanya melekatkan lilin pada kain putih yang biasa kita lakukan pada saat sekarangng ini, tetapi dari abat ke- 8 para ilmuan sudah melakukan eksperimen dari material-material alami seperti proses pembuatan batik tanah liek juga mengunakan tanah sebagi media pewarnaan batiknya.

\section{Motif Batik}

Susanto (1980:212) bahwa "Motif batik adalah kerangka gambar yang mewujudkan batik secara keseluruhan. Motif disebut juga corak batik atau pola batik". Maka motif batik secara keseluruhan adalah menggambarkan tentang kehidupan ini tidak mudah tetapi tergantung dari perbuatan dan pengendalian hidup manusia itu sendiri. Menurut Kamus Besar Bahasa Indonesia (1999:593) "Motif pola bentuk dasar dalam menciptakan atau perujudan suatu ornamen". Rangkaian alam-alam dibentuk seindah mungkin melalui sentuhan unsur rupa seperti garis yang akan memaksimalkan tampilan suatu perujudan. Begitulah kira-kira penggambaran motif secara verbal.

\section{1).Ornamen}

Kusrianto (2013:5) menurut unsurnya motif batik ada dua bagian utama yaitu: ornamen motif batik dan isenisen motif batik. Ornamen motif batik terdiri atas ornamen utama dan ornamen pengisi bidang, yaitu:

(1) Ornament pokok atau utama berbentuk stilasi dari benda alam atau hewan, melambangkan suatu 


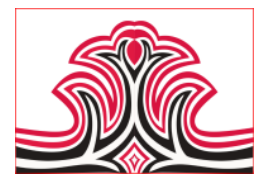

makna, mempunyai arti filosofis, seperti ornamen meru, pohon hayat, ular atau naga, lidah api dan sebagainya. Biasanya berukuran cukup besar atau dominan dalam sebuah motif.

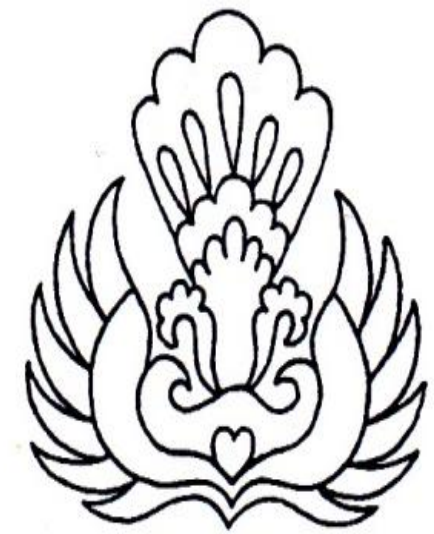

Gambar 1. Ornamen Utama (Sumber: Kusrianto, 2013:16)

(2) Ornamen pelengkap atau pengisi bidang adalah orname yang dibuat untuk mengisi bidang yang kosong di samping ornament pokok. Ornament pelengkap tidak mepunyai arti atau makna tertentu kecuali untuk melengkapi hiasan dan keindahan. Minsalnya ornamen tumbuhan seperti pohon, bunga, daun dan hewan seperti burung, kupu-kupu, ikan, merak, ayam dan sebagainya.

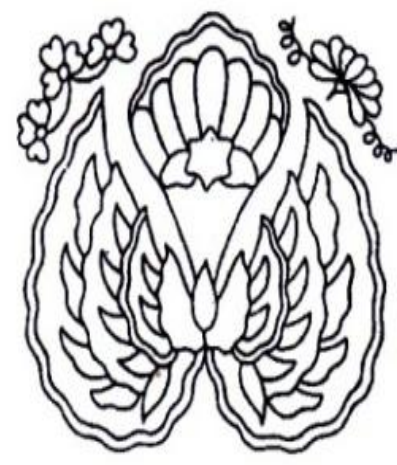

Gambar 2. Ornamen Utama (Sumber: Kusrianto, 2013:16)

\section{2).Isen-Isen}

Isen (isian) berupa titik, garis-garis gabungan titik dan garis yang berfungsi untuk mengisi bidang diatntara ornamen-ornamen tersebut. Isen motif ada bermacammacam dan sekarang masih berkembang, seperti: cecek, cecek pitu, sisir melik, cecek sawut, cecek sawu daun, sisir grinsik, galaran, rambutan, sirapan, cecah gori, dan sebagainya.
Gorga Jurnal Seni Rupa

Volume 08 Nomor 01 Januari-Juni 2019

p-ISSN: 2301-5942 | e-ISSN: 2580-2380

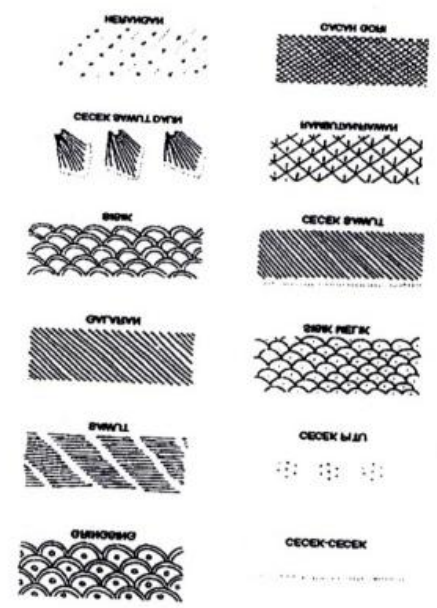

Gambar 3. Macam Isen-isen (Sumber: Kurianto, 2013:28)

\section{Penggolongan Motif Batik}

Berdasarkan susunan dan bentuk ornamen di dalam motif-motif, maka motif-motif batik tersebut sampai perkembangan dewasa ini dapat dibedakan penggolongan dan pembagiannya. Susanto (1980:215) membagi penggolongan motif menjadi dua kelompok besar yaitu:

1) Golongan motif geometris yaitu motif-motif yang tersusun atau unsur-unsur bentuk geometris, seperti: lingkaran, segi empat, segi tiga dan sebaginya.

2) Golongan Naturalis yaitu motif-motif yang ornamen utamanya terdiri dari tumbuhan, meru, burung atau lar-laran, dan binatang, yang tersusun secara harmoni tetapi tidak menurut bidang-bidang geometris, golongan ini disebut Semen.

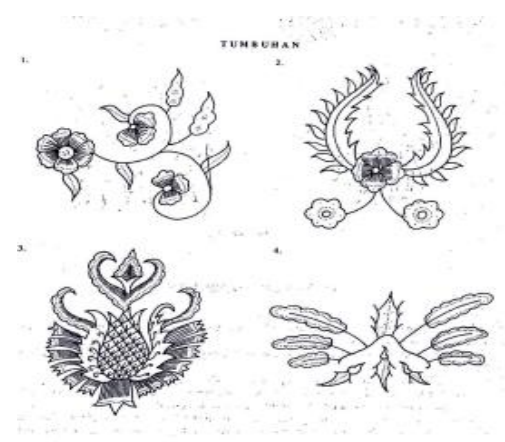

Gambar 4. Motif Tumbuhan (Sumber: Sewan Susanto, 1980:264) 

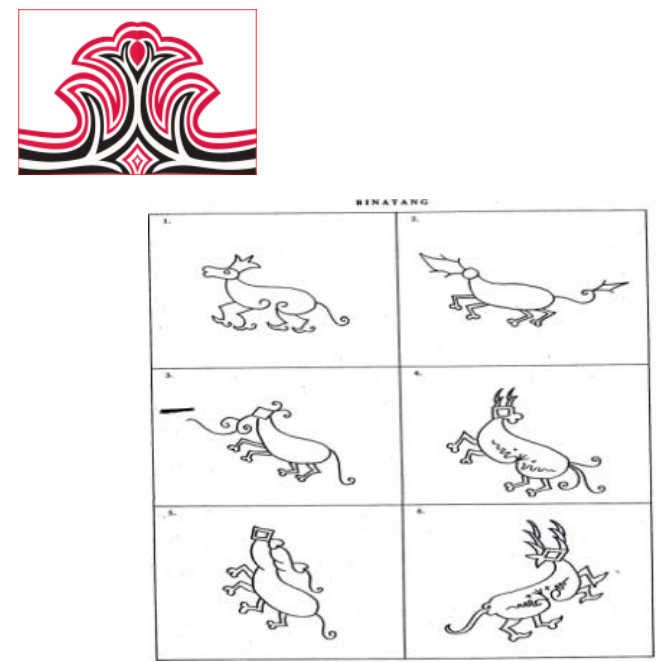

Gambar 5. Motif Binatang (Sumber: Sewan Susanto, 1980:275)

\section{METODE PENELITIAN}

Penelitian ini menggunakan metode deskriftif dengan pendekatan kualitatif. Arikunto (2010:3) mengemukakan bahwa, "Penelitian deskriftif adalah penelitian yang dimaksudkan untuk menyelidiki keadaan, kondisi atau hal lain yang sudah disebutkan dan hasilnya dapat dipaparkan dalam bentuk laporan penelitian". Jenis data dalam penelitian ini adalah data primer dan data sekunder. Dalam penelitian kualitatif yang menjadi instrumen atau alat penelitian adalah peneliti itu sendiri. Teknik pengumpulan data dilakukan dengan cara observasi (pengamatan), wawancara dan dokumentasi. Teknik analisa data yang dilakukan yaitu teknik analisa model interaktif yaitu yang berkaitan dengan pokok permasalahan penelitian. Dalam penelitian kualitatif untuk mendapatkan data yang valid, maka ada beberapa hal yang harus dilakukan oleh peneliti dalam teknik pemeriksaan keabsahan data yaitu: perpanjangan pengamatan, meningkatkan ketekunan, trianggulasi, pengecekan teman sejawat dan auditing.

\section{HASIL DAN PEMBAHASAN}

\section{Hasil}

\section{1).Asal Usul Batik Tanah Liek Citra Monalisa}

Berdasarkan hasil penelitian dan hasil wawancara dengan pimpinan dan sekaligus seorang wanita yang mengankat kembali salah satu warisan budaya Minangkabau yaitu batik tanah liek. Hj. Wirda Hanim berusia (66th) kelahiran Batusangkar, Kabupaten Tanah Datar, Sumatera Barat. Ibu Wirda Hanim menjelaskan pada tahun 1993 beliau pernah mengahdiri upacara adat dikampung di Nagari Sumanik Kecamatan Salimpuang, Tanah Datar, beliau memperhatikan salah satu kain selendang yang dikenakan Bundo Kandung setempat yang tampak kusam dan sudah mulai robek-robek.
Gorga Jurnal Seni Rupa

Volume 08 Nomor 01 Januari-Juni 2019

p-ISSN: 2301-5942 | e-ISSN: 2580-2380

Ibu Wirda Hanim juga menjelaskan bahwa menurut Bundo Kandung setempat selendang yang di pakainya itu merupakan kain tanah liek dan juga diperkuat dari keterangan ahli waris Kerajaan Pagaruyung, Agustin Puti Reno Raudhatul Jannah Tahib menjelaskan motif kain batik tanah liek tersebut berasal dari Cina.Asal batik tanah liek ini diduga dari negri Cina yang diduga masuk ke Minangkabau pada abat ke-16 pada zaman kerajaan Minangkabau berpusat di Pagaruyung, Batusangkar.Batiktanah liek adalah batik khas Minangkabau, walaupun tak ada catatan sejarah sejak kapan kerajinan batik tanah liek muncul ke Sumatera Barat.Diduga batik ini muncul ketika pengaruh kebudayan Cina masuk ke wilayah alam Minangkabau dan setelah itu sempat hilang tanpa jejak pada masa penjajahan Jepang.

Melihat kejadian tersebut timbul semangat Ibu Wirda Hanim untuk memahami tentang batik tanah liek secara mendalam Ibu Wirda Hanim waktu itu berpropesi sebagai pengusaha dibidang bordir, usaha yang dirintis di Kota Padang bersama bersama suaminya. Beliau sangat awam dengan proses pembutan kain batik, karena rasa ingin tau yang besar tentang cara pembuatan batik tanah liek tersebut, ibuWirda Hanim melakukan eksperimen sendiri. Berkali-kali beliau melakukan eksperimen sendiri, namun usahanya tersebut sering gagal.

Tak sampai disitu, ibu Wirda Hanim terus memupayakan berbagai cara untuk bisa membuat batik tanah liek seperti yang di pakai oleh Bundo Kandung di kampungnya, termasuk mengikuti kursus membatik dari Yogyakarta dan mendatangkan langsung pembatik asal Yogyakarta. Namun hasilnya belum memuaskan dan sudah mengahabiskan biaya berkisar Rp.20.000.000,00 untuk modal membeli kain sutra, katun, obat-obatan batik, dan peralatan membatik.

Enam bulan setelah itu beliau menemukan selendang yang disebut tanah liek, beliau mencoba mengikuti pelatihan batik yang digelar Dewan Kerajinan Nasional Daerah (Dekranasda) Sumbar.Waktu itu dipimpin oleh Zuraida Manan, istri Hasan Basri Durin, Gubernur Sumbar priode 1987-1997. Pada pelatihan tersebut proses pembuatan batik tanah liek, tetapi mengunakan bahan sintetis dan tidak satupun ada proses pengerjaan yang menggunakan tanah liat. Ibu Wirda Hanim melakukan lagi eksperimen sendiri, beliau mencoba mengaplikasikan tanah liat dalam pewarnaan dasar.Beliau bahkan merendam kain sutra selama empat hari, bertujuan untuk membuat warna tanah liat benar-benar melekat pada kain. Berkat 


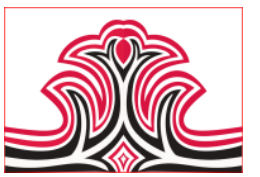

kegigihan beliau tersebut akirnya eksperimennya berhasil dan hasilnyapun sesuai dengan selendang batik tanah liek yang asli dari Bundo Kandung.

Dari situlah beliau meyakini dan memastikan bahwa proses pembuatan batik tanah liek merupakan warna dasar alami yang dihasilkan berasal dari perendaman kain dengan menggunakan tanah liat. Dari segi motif ibu Wirda Hanim meniru motif batikurang lamo (orang-orang terdahulu) yaitu terdapat motif kuda laut dan burung hong.Ibu Wirda Hanim juga terinspirasi dari motif alam Minangkabau, beliau meniru dan menstilasi kembali motif asli ukir Minangkabau.

Pada tahun 1994 ibu Wirda Hanim mulai memproduksi batik tanah like, untuk pemasaran beliau mengaku banyak mendapat bantuan dariZuraida Manan, istri Hasan Basri Durin, Gubernur Sumbar priode 1987-1997. Zuraida mengkampanyekan agar anggota Darma Wanita dan Bundo Kanduang Sumatera Barat memakai batik tanah liek dalam berbagai acara. Bahkan jika tamu dari luar daerah datang Wirda diminta membawa batik tanah liek-nya ke hotel tempat para tamu menginap. Para tamu cukup tertarik dan berminat pada batiktanah liek, sejak itu usaha batik menjadi membaik.

\section{2).Motif Batik Tanah Liek Citra Monalisa}

Batik tanah liek Citra Monalisa masih melestarikan motif dari adat istiaadat minang kabau, motifnya selau berkaitan dengan bentuk alam benda yang ada di daerah Sumatra Barat. Motif yang banyak diproduksi di batik tanah liek Citra Monalisa adalah motif rumah gadang, kabau padati, jam gadang, tabuik, kapal malin kundang, rangkiang,siriah gadang, kaluak paku, bunga melati, bungo rayo, dan burung hong. Motif batik tanah liek Citra Monalisa memiliki ragam hias naturalis dan dekoratif pada ornament utama, ornament pelengkap dan isen-isen.

Dalam mendesain bentuk motif, para pengrajin berkreasi dalam menciptakan bentuk motif baru, mereka mengkombinasikan bentuk alam, motif-motif minangkabau, tumbuh-tumbuhan dan sering juga para pengrajin memanfaatkan motif-motif yang sudah dibuat sebelumnya dengan cara mengembangkan motif tersebut sesuai dengan kreatifitas pengarajin. yang dibuat berdasarkan kepada desain yang sudah diciptakan sebelumnya, selain pengrajin.

Berdasarkan pengamatan yang peneliti lakukan motif batik tanah liek Citra Monalisa sangat erat kaitanya dengan lingkungan sekitarnya berupa adat budaya daerah, fauna dan flora.Motif batik tanah liekdi Citra
Gorga Jurnal Seni Rupa

Volume 08 Nomor 01 Januari-Juni 2019

p-ISSN: 2301-5942 | e-ISSN: 2580-2380

Monalisa terdiri dari dua unsur yaitu ornamendan isen-isen. Ornamen dibedakan lagi atas ornamen utama dan ornamen pelengkap (pengisi bidang), namun ada sebagian motif batik yang tidak memiliki isen-isen.Ini adalah beberapa contoh motif batik tanah liek citra monalisa. Sebagai berikut:

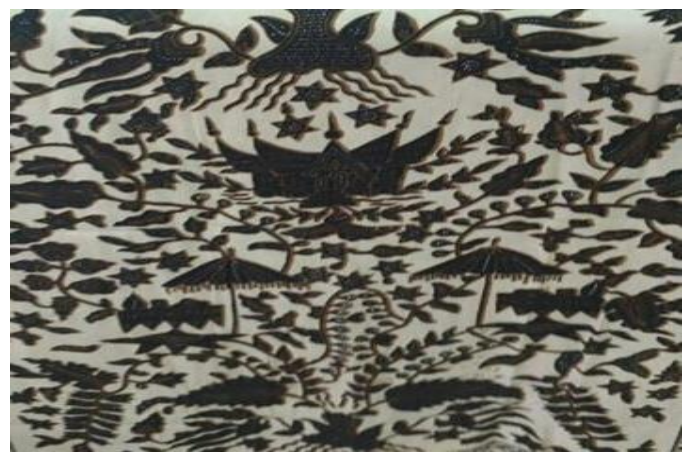

Gambar 6. Motif Rumah Gadang

(Sumber: Nana Oktora, 2016)

Gambar diatas merupakan batik tulis dengan motif ragam hias bentuk dekoratif dari bentuk motif alam benda, motif tersebut beridekan dari rumah gadangkhas minangkabau yang menjadi ornamen utama pada motif. Selainmotif utama terdapat pula motif tambahan seperti isen-isen berbentukbungabunga dan motif tumbuh-tubuhan sebagai pengisi bidang. Dari penjelasan tersebut dapat diketahui bahwa rumah gadang yang merupakan rumah adat minang kabau dan payung yang biasanya dipakai pada acara-acara adat dijadikan sebagai motif utama lalu dipadukan dengan motif naturalis sebagai motif pelengkapnya.

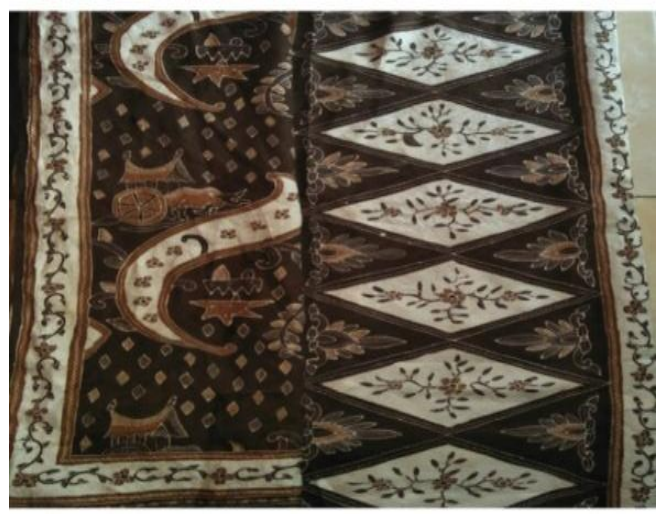

Gambar 7. Kabau Pedati (Sumber: Nana Oktora, 2016)

Gambar di atas merupakan batik tulis dengan motif ragam hias dekoratif dari bentuk alam benda, motif tersebut beridekan dari kabau padati yang terdapat pada motif utama.Selain motif utama terdapat pula motif tambahan seperti isen-isen berbentuk itik pulang 


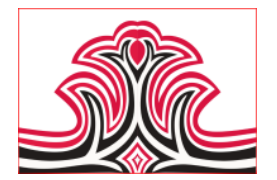

patang, bunga-bunga dan tumbuhan lainya sehingga terbentuk sebuah desain yang harmoni dan seimbang.

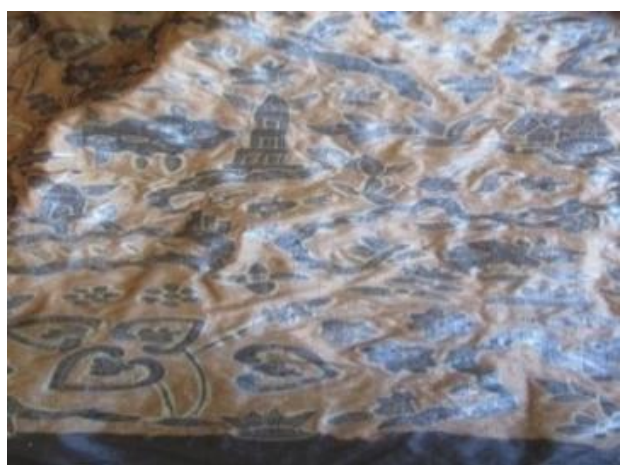

Gambar 8. Jam Gadang

(Sumber: Nana Oktora, 2016)

Gambar di atas merupakan batik tulis dengan motif ragam hias dekoratif dari bemtuk motif alam benda, motif tersebut beridekan dari jam gadang yang terdapat pada motif utama.Selain motif utama terdapat pula motif tambahan isen-isen berbentuk tumbuhtumbuhan dan motif dedaunan sebagai pengisi bidang.

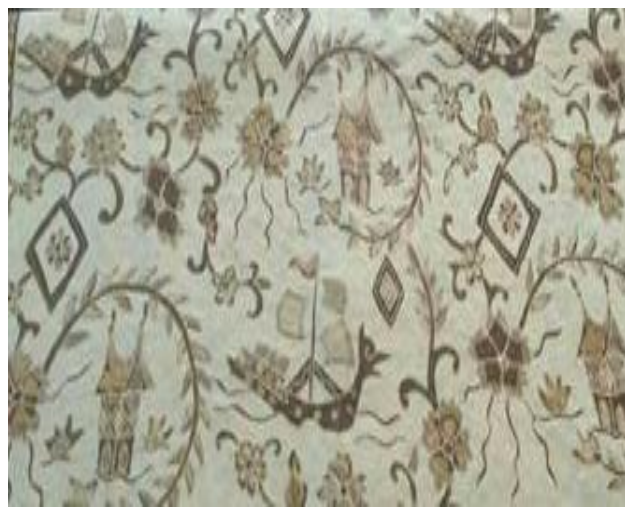

Gambar 9. Kapal Malin Kundang (Sumber: Nana Oktora, 2016)

Gambar diatas merupakan batik tulis dengan motif ragam hias dekoratif dari bentuk motif alam benda, motif tersebut ber idekan dari kapal malin kundang yang terdapat pada motif utama.Selain itu teredapat motif tambahan kaluak paku sebagai isen-isen.
Gorga Jurnal Seni Rupa

Volume 08 Nomor 01 Januari-Juni 2019

p-ISSN: 2301-5942 | e-ISSN: 2580-2380

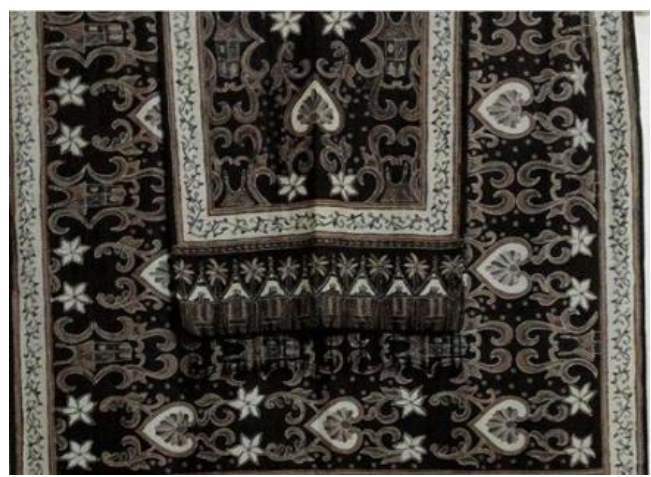

Gambar 10. Daun Sirih

(Sumber: Nana Oktora, 2016)

Gambar di atas merupakan batik tulis dengan motif ragam hias naturalis dari bentuk motif flora, motif tersebut beridekan dari siriah gadang (daun siriah) sebagai motif utama.Selain motif utama terdapat pula motif tambahan seperti isen-isen berbentuk motif rumah gadang, kipeh-kipeh yang berukuran kecil di buat pada pingiran kain. Kaluak paku sebagai ornament pelengkap untuk pengisi bidang desain tersebut.

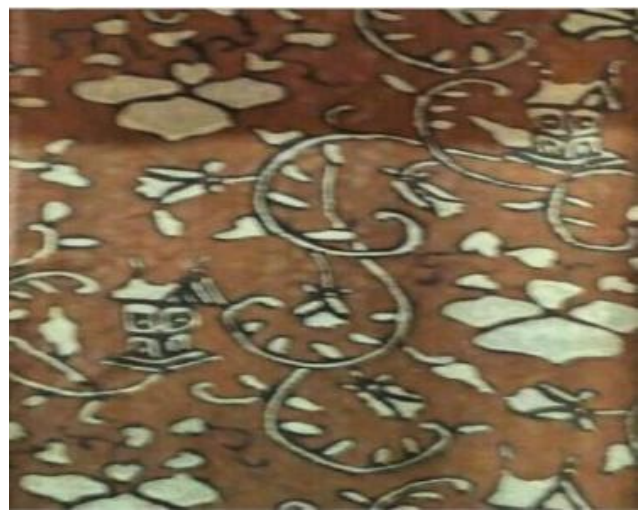

Gambar 11. Bunga Melati (Sumber: Nana Oktora, 2016)

Gambar di atas merupakan batik tulis dengan motif ragam hias bentuk naturalis dari bentuk motif flora, motif tersebut beridekan bunga melati dan rangkiang sebagai ornament utama,kaluak paku sebagai ornament pelengkap dan sebagi pengisi bidang. Dari penjabaran tersebut dapat disimpulkan bahwa motif bungo melati menjadikan bunga melati dan rangkiang sebagai ornamen utamannya dan kaluak paku sebagai ornamen pelegkap. 

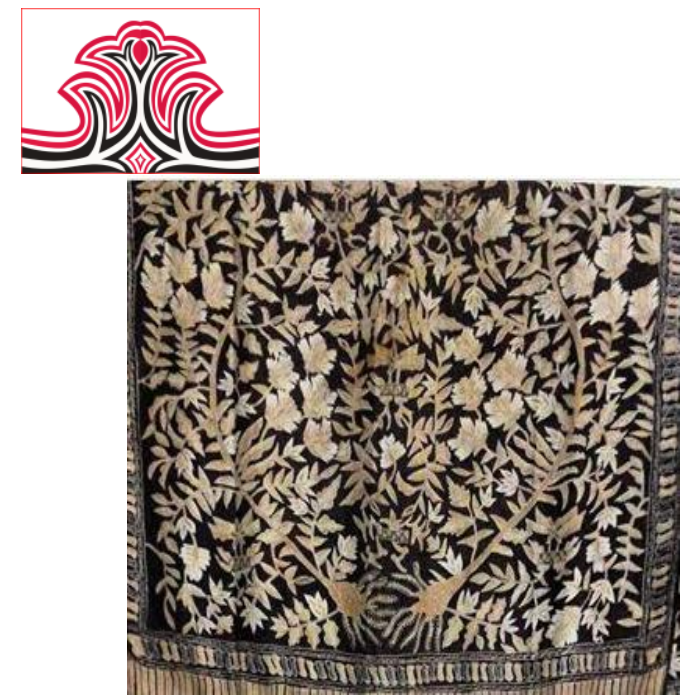

Gambar 12. Bunga Rayo

(Sumber: Nana Oktora, 2016)

Gambar diatas merupakan batik tulis dengan motif ragam hias naturalis dari bentuk flora, motif tersebut beridekan bungo rayo sebagai ornament utama dan daun-daunan seagai ornament pelengkap. Dari penjelasan tersebut disimpulkan bahwa motif bungo rayo merupakan bentuk motif naturalis yang menjadikan bunga kembang sepatu sebagai motif utamanya.Ornamen pelengkapnya berupa daun-daun.

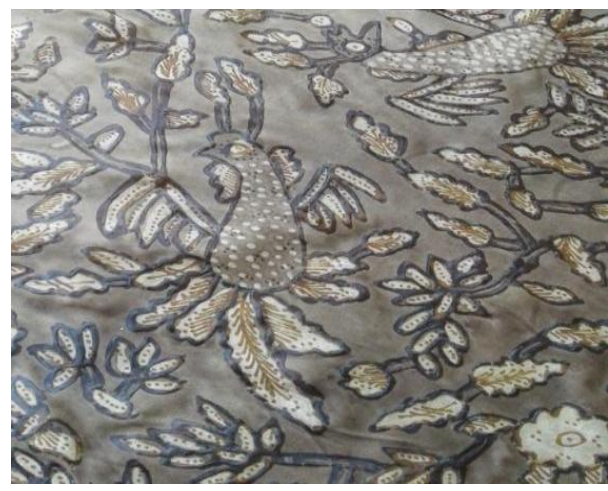

Gambar 13. Burung Hong

(Sumber: Nana Oktora, 2016)

Gambar diatas merupakan batik tulis dengan motif ragam hias naturalis dari bentuk fauna, motif tersebut beridekan dari burung hong, sebagai motif utama.Selain motif utama terdapat pula motif pelengkap seperti daun-daunan.Motif burung hong merupakam desain motif batik tanah liek yang sudah ada dari zaman dahulu dan merupakan desain motif khas batik pada umumnya. Disetiap usaha batik dan di daerah penghasil batik, desain motif burung hong selalu ada, mempunyai ciri khas sesuai kratifitas dan ide-ide masing-masing. Bentuk stilasi dan variasinya berbeda-beda serta ditambahan dengan bentuk desain motif yang lain tanpa mengubah bentuk asli dari burung hong tersebut.
Gorga Jurnal Seni Rupa

Volume 08 Nomor 01 Januari-Juni 2019

p-ISSN: 2301-5942 | e-ISSN: 2580-2380

Dari penjelasan di atas dapat diketahui bahwa motif burung hong merupakan desain motif khas batik dari zaman dahulu.Burung hong sangat lekat dengan kehidupan warga tiongha.Burung hong sering jadikan dekorasi pernikahan yang biasanya diasandingkan dengan naga dan menjadi simbol hubungan mesra antara suami istri. Pemaisuri kaisar China dan putriputri istana pun tutut menggunakan burung hong sebagai motif utama di pakaian utuk perayaan hari besar China. Jadikan desain motif burung hong ini terispirasi dari legenda kahaisar China. Di batik tanah liek citra monalisa juga mempunyai desain motif batik burung hong yang sudah distilasi dan mempunyai ciri khas tersendiri.

\section{Pembahasan}

\section{1).Motif Batik Tanah Liek Citra Monalisa}

Batik tanah liek Citra Monalisa masih melestarikan motif dari adat istiaadat minang kabau, motifnya selau berkaitan dengan bentuk alam benda yang ada di daerah Sumatra Barat. Motif yang banyak diproduksi di batik tanah liek Citra Monalisa adalah motif rumah gadang, kabau padati, jam gadang, tabuik, kapal malin kundang, rangkiang,siriah gadang, kaluak paku, bunga melati, bungo rayo, dan burung hong. Motif batik tanah liek Citra Monalisa memiliki ragam hias naturalis dan dekoratif pada ornament utama, ornament pelengkap dan isen-isen.

Hal ini sesuai dengan ahli Ernawati (2008:387) mengatakan bahwa "1) Bentuk naturalis yaitu bentuk yang dibuat berdasarkan bentuk yang ada di alam sekitar seperti bentuk tumbuh-tumbuhan, bentuk hewan atau binatang, bentuk batu-batuan,bentuk awan, matahari, binatang, bentuk pemandangan alam dan lain-lain; 2) Bentuk geomtris yaitu bentuk-bentuk yang mempunyai bentuk teratur dan dapat di ukur mengunakan alat ukur; 3) Bentuk dekoratif merupakan bentuk yang berasal dari bentuk naturalis dan bentuk khas bentuk tersebut masih terlihat."geomtris yang sudah distilasi atau direngga sehingga muncul bentuk baru tetapi ciri”.

\section{KESIMPULA DAN SARAN}

\section{Kesimpulan}

Desain motif batik Tanah Liek Citra Monalisa Sawahan Padang dibuat oleh pengrajin itu sendiri. Didalam mendesain bentuak motif perkriya batik berkreasi sendiri dengan mengambil bentuk alam, tumbuh-tumbuhan, binatang maupun motif Minangkabau. 


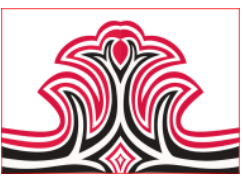

2.Saran

Berdasarkan hasil penelitian yang telah penulis lakukan, maka penulis menyarankan hal-hal sebagai berikut:

1) Kepada pengrajin batikTanah Liek Citra Monalisa Sawahan Padang supaya terus berkarya dan mengembangkan pengetahuannya dibidang batik terkhusus batik Tanah Liek baik dari segi bahan, motif, dan teknik pembuatan

2) Kepada Dinas Pemerintah, Kebudayaan, dan Pariwisata untuk melestarikan dan mengapresiasi karya-karya batik Tanah Liek di Sumatera Barat terutama di Kota Padang, sehingga sudah diwarisi ini bisa terjaga sampai generasi selanjutnya.

3) Diharapkan kehadiran karya tulis ilmiah ini dapat menggungah pembaca untuk melakukan yang lebih mendalam mengenai batik Tanah Liek.

\section{DAFTAR RUJUKAN}

Arikunto, Suharsimi. (2010). Prosedur Penelitian. Jakarta: Rinike Cipta.

Elliot. (2004). Batik Tulis. Jakarta: Gramedia.

Hamzuri. (1981). Batik Klasik. Jakarta: IKAPI.

Kamus Besar Bahasa Indonesia. (2007). Departemen Pendidikan Nasional: Balai Pustaka.

Karmila, Mila. (2010). Ragam Kain Tradisional Nusantara, Makna, Simbol dan Fungsi. Jakarta: Bee Media Indonesia.

Kusrianto, Adi. (2013). Batik- Filosofi, Motif dan Kegunaan. Yogyakarta: Andi.

Santaso, Ratna Endah. (2010). Anggun Dengan Selembar Kain Batik. Yogyakarta: Saka Mitra Kompetensi.

Sewan, Susanto S. Teks. (1980). Seni Kerajinan Batik Indonesia. Yogyakarta: Balai Penelitian Batik dan Kerajinan. 